\title{
Método para classificação de tipos de erros humanos: estudo de caso em acidentes em canteiros de obras
}

\author{
Tarcisio Abreu Saurin ${ }^{\mathrm{a} *}$, Mara Lucia Grando \\ Marcelo Fabiano Costella ${ }^{c}$ \\ a*saurin@ufrgs.br, UFRGS, Brasil \\ bmaralucia35@gmail.com, UCEFF, Brasil \\ ccostela@unochapeco.edu.br, Unochapecó, Brasil
}

\begin{abstract}
Resumo
Este trabalho tem como objetivo principal desenvolver melhorias em um método de classificação de tipos de erros humanos de operadores de linha de frente. Tais melhorias foram desenvolvidas com base no teste do método em canteiros de obras, um ambiente no qual ele ainda não havia sido aplicado. Assim, foram investigados 19 acidentes de trabalho ocorridos em uma construtora de pequeno porte, sendo classificados os tipos de erros dos trabalhadores lesionados e de colegas de equipe que se encontravam no cenário do acidente. Os resultados indicaram que não houve nenhum erro em 70,5\% das 34 vezes em que o método foi aplicado, evidenciando que as causas dos acidentes estavam fortemente associadas a fatores organizacionais. 0 estudo apresenta ainda recomendações para a interpretação das perguntas que constituem o método, bem como modificações em algumas dessas perguntas em comparação às versões anteriores.
\end{abstract}

Palavras-chave

Investigação de acidentes. Erro humano. Segurança no trabalho. Construção civil.

\section{Introdução}

Há amplo consenso, sob a perspectiva da ergonomia, de que os erros humanos são sintomas de problemas mais profundos em um sistema, ao invés de serem a principal causa de eventos indesejados. Assim, a identificação dos erros é apenas o ponto de partida de uma investigação, podendo levar a ações preventivas com um amplo espectro, desde treinamentos ao reprojeto de processos e produtos (DEKKER, 2002). Contudo, a literatura indica que cada tipo de erro possui determinados padrões causais, o que significa que as ações preventivas devem ter diferentes ênfases para cada tipo de erro (REASON, 2008). Por exemplo, o uso de dispositivos à prova de erros é particularmente indicado para combater lapsos de memória e deslizes, visto que esses tipos de erros ocorrem durante comportamentos automatizados, e tais dispositivos, por definição, funcionam independentemente da atenção dos operadores. Já as violações, caracterizadas por desvios deliberados dos métodos de trabalho seguros, tipicamente requerem melhorias nos procedimentos ou melhorias na cultura de segurança (SAURIN et al., 2008).

Deste modo, o conhecimento dos tipos de erros mais frequentes, especialmente com base em dados que permitam identificar tendências de longo prazo, constitui importante informação para o projeto de sistemas de gestão da segurança e saúde no trabalho (SST). As classificações de tipos de erros são úteis visto que viabilizam a organização dos dados e contribuem para a compreensão acerca dos modos pelos quais eles são causados e como podem ser prevenidos (SANDERS; McCORMICK, 1993). Entretanto, a literatura oferece poucos métodos para minimizar a subjetividade envolvida na classificação de um erro. Além disso, as classificações existentes assumem a existência de tipos de erros mutuamente exclusivos, o que pode ser uma simplificação demasiada e fonte de incerteza nas tabulações de dados (GRABOWSKl et al., 2009). 
Baker e Krokos (2007) também criticam a falta de métodos para comparar as diferentes classificações, o que dificulta a identificação de quais são melhores para quais propósitos. Dentre os métodos disponiveis para classificar erros, este estudo aborda aquele proposto por Costella e Saurin (2005), o qual foi originalmente desenvolvido e testado na análise de acidentes em uma fábrica de máquinas agrícolas. Posteriormente, Bassols, Ballardin e Guimarães (2007) aperfeiçoaram a ferramenta com base na análise de acidentes em uma distribuidora de combustíveis. 0 estudo de Saurin et al. (2008) comparou os resultados dos estudos anteriores e propôs pequenas modificações adicionais nas versões anteriores do método.

Basicamente, o método consiste de um algoritmo com uma série de perguntas, com respostas do tipo sim ou não, que permite classificar os tipos de erros de operadores de linha de frente com base na classificação SRK (skill, rule and knowldege based errors) proposta por Reason (1990, 1997). Nessa classificação, os erros são diferenciados de acordo com os níveis de desempenho cognitivo em que eles ocorrem, constituindo uma classificação mais abstrata do que aquelas baseadas em características observáveis de comportamento (por exemplo, omissões e repetições), bem como classificações que destacam fatores locais contextuais, tais como estresse, interrupções e distrações (REASON, 2008).

Neste contexto, o presente estudo tem como objetivo apresentar recomendações para facilitar a aplicação e a interpretação das perguntas do algoritmo, visto que os estudos até então realizados indicaram dificuldades dessa natureza. De fato, algoritmos para investigação de acidentes similares ao abordado neste trabalho têm sido criticados em função das diversas possibilidades de interpretação de perguntas cujas respostas são aparentemente simples (DEKKER, 2007). As melhorias no método foram identificadas com base na sua aplicação para a investigação de acidentes ocupacionais na construção civil, um ambiente no qual ele ainda não havia sido testado. Além disso, diferentemente das aplicações anteriores, os pesquisadores puderam entrevistar todos os trabalhadores lesionados e não foram utilizados relatórios de investigações realizadas pela empresa, as quais não existiam. Desta forma, o contexto de aplicação da ferramenta foi claramente diferente dos estudos anteriores, o que contribuiu para a identificação de oportunidades de melhoria. Além disso, a aplicação do método gerou dados exploratórios acerca dos tipos de erros humanos mais frequentes entre trabalhadores da construção civil, os quais são escassos na literatura.

\section{Definição de erro humano e classificação de tipos de erros adotada nesse estudo}

Embora não exista uma definição de erro humano amplamente aceita, características comuns podem ser identificadas nas diversas definições disponíveis. De acordo com Reason (1990), erro humano é um termo genérico para designar as ocasiões em que uma sequência planejada de atividades mentais ou físicas não atinge seus objetivos, sem que a falha possa ser atribuída ao acaso. Já Sanders e McCormick (1993) consideram que erro humano é uma decisão ou comportamento inapropriado que reduz, ou tem o potencial de reduzir, a eficiência, a segurança ou outras dimensões do desempenho de um sistema. Reason (2008) considera que, na interpretação majoritária na literatura acadêmica, os erros envolvem algum tipo de desvio, como, por exemplo, a partir do método de execução ou de um plano. Nesse ponto de vista, especialmente em sistemas altamente padronizados, é mais fácil rotular uma falha como um erro humano, em comparação a atividades menos padronizadas, tais como manutenções ou construção civil (RASMUSSEN; PETERSEN; GOODSTEIN, 1994).

Neste trabalho, considera-se que um erro humano tem uma ou ambas das seguintes características: houve um desvio em relação ao método de execução correto, sendo que aqueles que executavam a tarefa tinham os recursos disponiveis para executar o método correto; houve uma tomada de decisão incorreta, sendo que os recursos para a tomada de decisão correta estavam disponíveis. Vale salientar que a definição adotada não significa que necessariamente um erro humano leva a resultados indesejados, visto que o acaso pode levar a bons resultados mesmo havendo falhas de planejamento ou execução. Conforme já comentado, neste estudo é adotada a classificação SRK proposta por Reason (1990, 1997), a qual divide os erros em três categorias:

- Erros no nível da habilidade (skill-based errors, SB): nesse nível, o operador realiza comportamentos automáticos e rotineiros, com baixo nível de consciência. Os erros tipicamente envolvem falhas de execução, sendo que os lapsos e deslizes são as mais comuns. Enquanto os lapsos geralmente envolvem falhas de memória, os deslizes são associados a falhas no reconhecimento de sinais e perturbações de qualquer natureza que interrompem os comportamentos automáticos. Os lapsos ou deslizes antecedem a detecção de um problema;

- Erros no nível das regras (rule-based errors, RB): nesse nível, o operador aumenta a consciência para aplicar regras familiares em desvios também familiares das situações rotineiras. Três tipos básicos de falhas 
podem ocorrer no nível RB: aplicação de uma má regra; aplicação de uma boa regra, mas inadequada ao cenário em questão; não aplicação de uma boa regra. Neste trabalho, apenas esse último tipo de falha RB é considerado como um tipo de erro de operadores de linha de frente, sendo designada pelo termo violação. Assume-se que a aplicação de más regras ou a aplicação de uma boa regra inadequada ao contexto, são tipos de erros que devem ser alocados a níveis hierárquicos mais altos, responsáveis pela concepção das regras;

- Erros no nível do conhecimento (knowledge-based errors, $\mathrm{KB}$ ): nesse nível o operador atua em alto nível de consciência para resolver problemas que não dispõem de regras. Os erros são bastante prováveis quando o operador é requisitado a operar nesse nível, dentre outros motivos pelo fato de que normalmente há pressões organizacionais que limitam o tempo e os recursos para a tomada de decisão.

$\mathrm{O}$ operador, quando comete um erro nos níveis $\mathrm{KB}$ ou RB, tem consciência de que um problema existe, havendo, portanto, intenção nas suas ações. De outro lado, os erros no nível SB são não intencionais, uma vez que as ações não foram adotadas conscientemente.

Cabe enfatizar que cada uma das três grandes categorias de erro pode ser adicionalmente dividida em subcategorias. Por exemplo, os lapsos de memória podem envolver falhas de armazenamento e falhas de recuperação de informações, enquanto as violações podem envolver violações rotineiras e violações necessárias (REASON, 2008).

\section{Algoritmo para classificação de tipos de erros humanos}

0 algoritmo proposto por Saurin et al. (2008) consiste de dez perguntas, as quais podem levar a cinco tipos de respostas finais (Figura 1): deslizes, lapsos de memória, violações, erros baseados no conhecimento e não houve erro do trabalhador. A pergunta 1 foi enunciada da seguinte forma: "o trabalhador conhecia os procedimentos e/ou foi treinado para esta tarefa?" Nesta questão, a palavra "tarefa" tem um significado amplo, referindo-se a um conjunto de operações realizadas para atingir determinado objetivo. Caso a resposta à pergunta 1 seja negativa, a pergunta 9 deve ser feita ("o trabalhador foi alocado por um superior para realizar essa tarefa?") podendo conduzir a um resultado final de violação ou de ausência de erro do operador.

Uma vez que a resposta à pergunta 1 seja positiva, a pergunta 2 deve ser feita para verificar se o procedimento e/ou treinamento eram adequados e aplicáveis para a tarefa em que ocorreu o acidente. Caso eles não sejam adequados e aplicáveis, o algoritmo indica que a resposta final deve ser "não houve erro do trabalhador". De outro lado, caso a resposta seja "sim", deve ser feita a pergunta 3: "o procedimento e/ou treinamento foi seguido?" Tal pergunta abre duas grandes ramificações no algoritmo. Em caso de resposta positiva, cabe perguntar se houve falha técnica (pergunta 4), que, se confirmado, indica que não houve erro dos operadores. Não tendo ocorrido falha técnica, deve ser questionado se o problema ocorreu no contexto de uma situação imprevista (pergunta 5). Sendo uma situação imprevista, fica caracterizado um erro que ocorreu quando o trabalhador operava no nível do conhecimento (erro KB). Sendo uma situação rotineira, fica caracterizado um deslize.

Já uma resposta negativa à pergunta 3 abre uma nova ramificação que começa pela pergunta 6 ("se o procedimento e/ou treinamento tivesse sido seguido, o incidente teria acontecido?"). Se a resposta for positiva, isso indica que as causas do evento não estavam vinculadas à qualidade dos procedimentos nem em conformidade com eles, levando à resposta "não houve erro do trabalhador". Em caso de resposta negativa, deve ser feita a pergunta 7 , denominada por Reason (1997) como teste da substituição (“outro trabalhador se comportaria do mesmo modo em uma mesma situação?”). Caso a conclusão seja de que outros trabalhadores agiriam da mesma forma, o algoritmo indica que "não houve erro do trabalhador".

De modo oposto, cabe fazer a pergunta 8 ("o comportamento foi intencional?”). Se o comportamento não foi intencional, fica caracterizado um lapso de memória. Caso contrário, fica caracterizada uma violação. Vale salientar que, após obter a conclusão acerca de qual tipo de erro ocorreu, ou obter a conclusão de que não ocorreu erro, sempre deve ser realizada a última pergunta do algoritmo ("houve outro trabalhador envolvido?”). Tal pergunta foi introduzida para enfatizar que o algoritmo deve ser aplicado para todos os que participavam da equipe de operadores envolvida no cenário do acidente, ao invés de apenas para o acidentado.

\section{Método de pesquisa}

Tendo em vista identificar oportunidades de melhoria no algoritmo, este foi aplicado na análise de acidentes ocorridos em uma empresa de pequeno porte, atuante na construção e incorporação de edifícios residenciais e comerciais. No período em que foi realizado esse estudo, a empresa contava com 70 trabalhadores nos seus canteiros de obras (nenhum terceirizado), além de 3 engenheiros civis e 1 arquiteta. 0 principal critério de escolha dessa empresa foi a facilidade de acesso dos pesquisadores aos dados necessários. A gestão da SST é caracterizada pela 


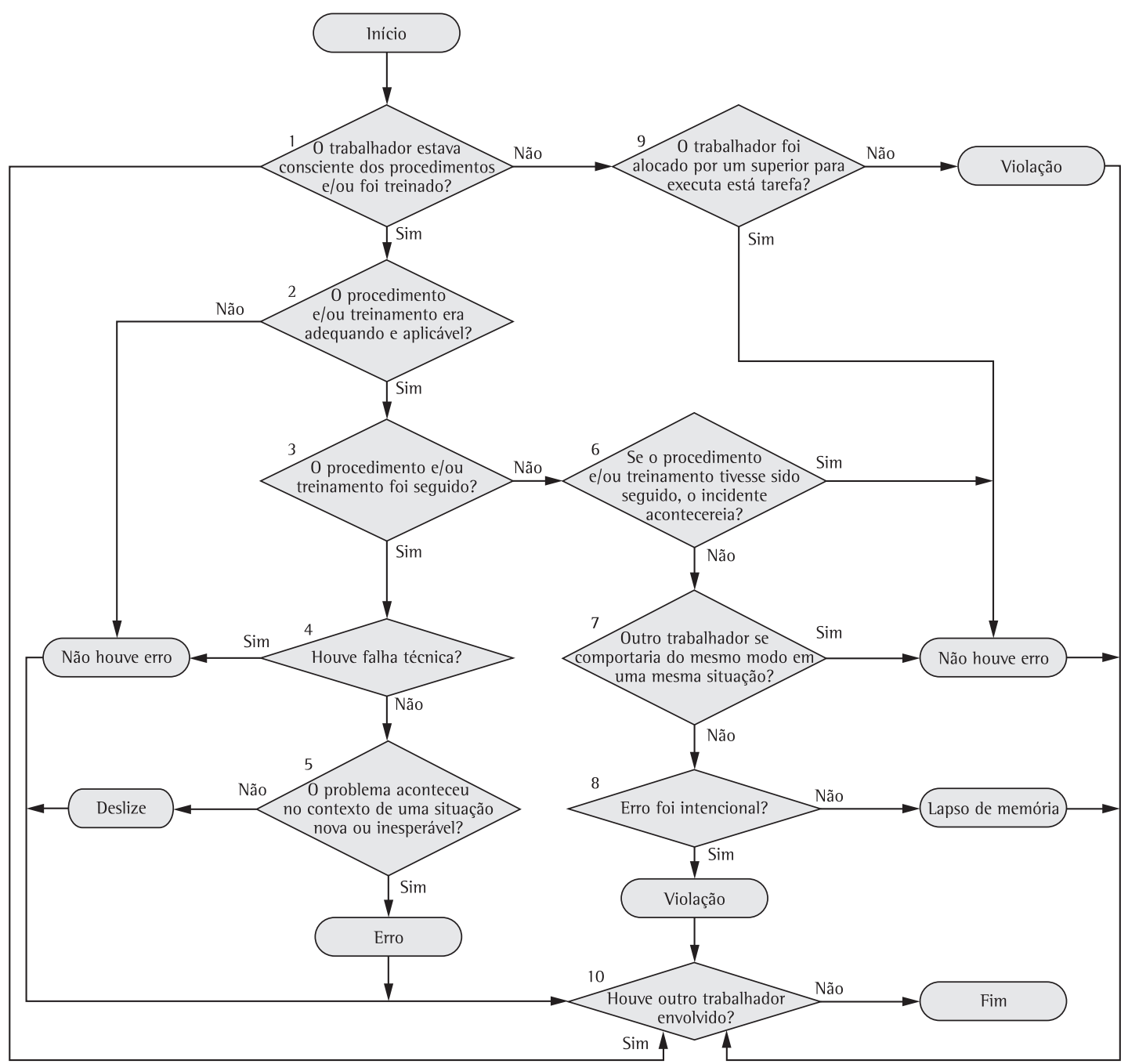

Figura 1. Algoritmo para classificação de tipos de erros humanos (SAURIN et al., 2008).

tentativa de estar em conformidade com a legislação, não havendo o uso de nenhuma prática associada ao desempenho de excelência em SST na construção civil, tais como aquelas identificadas por Hinze (2002). 0 principal responsável pela gestão da SST é um dos engenheiros civis, que também é engenheiro de segurança e desenvolve o PCMAT (Programa de Condições e Meio Ambiente de Trabalho na Indústria da Construção), documento exigido pela NR-18 (Condições e Meio Ambiente de Trabalho na Indústria da Construção). Embora exista uma CIPA (Comissão Interna de Prevenção de Acidentes) formalmente constituída, ela não tem se reunido periodicamente. Além disso, não existiam procedimentos para orientar a investigação de acidentes, nem havia registros documentados dos acidentes ocorridos.

Dessa forma, foi necessário que um membro da equipe de pesquisa visitasse as três obras da empresa que estavam em execução no período da pesquisa, questionando seus 70 trabalhadores, individualmente, se eles haviam sofrido ou presenciado algum acidente de trabalho na empresa estudada. Com base nesses questionamentos, foram identificados 26 acidentes. Contudo, apenas 19 eventos foram selecionados para inclusão nesse estudo, visto que nos demais casos os trabalhadores que sofreram as lesões, e que, portanto, poderiam acrescentar informações importantes, não eram mais funcionários da empresa.

$\mathrm{Na}$ etapa seguinte da pesquisa, foram realizadas entrevistas com os seguintes intervenientes e na seguinte sequência: a) com os trabalhadores lesionados; b) com os trabalhadores que estavam na equipe em que o acidentado trabalhava; c) com os três engenheiros da empresa. Tais entrevistas visaram esclarecer o contexto em que cada evento ocorreu, apoiar a compreensão de suas causas e obter subsídios para a aplicação do 
algoritmo. No que diz respeito aos trabalhadores (31 entrevistas ao todo), as entrevistas duraram, em média, cerca de 30 minutos e não foram gravadas, tendo em vista minimizar constrangimentos ou inibições. As entrevistas com os trabalhadores tiveram três etapas:

- Inicialmente, eles foram solicitados a prestar informações que permitissem uma caracterização básica do seu perfil e da severidade do evento, tais como: tempo de trabalho na empresa; escolaridade; idade; cargo; ano de ocorrência do evento; tempo de afastamento ocasionado pelo evento;

- Em seguida, a pesquisadora solicitou que o entrevistado contasse a sua versão do acidente para, com base nisso, contar-lhe de volta a história e verificar se houve entendimento correto do que realmente aconteceu;

- Na última etapa, foram realizadas perguntas baseadas em um roteiro desenvolvido por Dekker (2002) para apoiar a compreensão do contexto organizacional que levou aos erros humanos. Tal roteiro deu origem a outros questionamentos no decorrer da entrevista e incluiu perguntas como as seguintes: situação semelhante já aconteceu anteriormente? Você foi treinado para lidar com essa situação ou era uma situação nova ou imprevista? Quais regras de segurança ou de execução se aplicam claramente nessa situação de trabalho? Estas regras foram seguidas? A tarefa foi realizada sob pressões de tempo, custo ou outras? Você acha que outro colega faria o mesmo que você fez ou faria diferente?

Já as entrevistas com os engenheiros foram realizadas para esclarecer aspectos técnicos relativos a cada evento, tais como verificar se os procedimentos de execução utilizados no momento do acidente eram os usuais na empresa. Além disso, foram feitos registros fotográficos do ambiente em que cada evento ocorreu. Cabe salientar que a possibilidade de realizar entrevistas com os trabalhadores e engenheiros, bem como o irrestrito acesso aos canteiros de obras, permitiu que os eventos fossem conhecidos com relativa riqueza de detalhes, principalmente em comparação aos estudos anteriores de aplicação do algoritmo, que foram baseados em relatórios existentes nas próprias empresas, os quais geralmente eram superficiais.

Depois das entrevistas, uma descrição detalhada de cada acidente foi realizada e o algoritmo foi aplicado sob a perspectiva de cada um dos trabalhadores lesionados e sob a perspectiva de cada membro da equipe. Contudo, nessa primeira rodada de aplicações, os pesquisadores perceberam dificuldades na interpretação das perguntas, sendo, por vezes, o resultado obtido incoerente com o contexto do evento. Dessa forma, algumas modificações foram introduzidas no algoritmo, e os resultados apresentados neste artigo refletem as aplicações com base na versão modificada da ferramenta.

\section{Resultados}

\subsection{Recomendações para aplicação do algoritmo}

Neste item são apresentadas recomendações para aplicação do algoritmo não explicitadas nos estudos anteriores, ilustrando-as com base nos acidentes investigados:

- Recomendação 1: antes de iniciar a aplicação, devem ser identificados, a partir da descrição do acidente, episódios que sirvam de referência para a análise dos tipos de erros. Tais episódios podem ser tanto decisões tomadas pelos operadores, quanto ações realizadas por eles. No estudo de caso, a necessidade de adotar essa sistemática ficou clara nos eventos em que, além de ter ocorrido uma ação imediatamente desencadeadora ao acidente, o trabalhador também não usava os equipamentos de proteção individual (EPI) necessários. Nessas situações, o algoritmo foi aplicado uma vez para analisar a ação e outra vez para analisar a decisão de não usar o EPI.

Como exemplos, podem ser citados dois acidentes similares em que serventes, não usando luvas, tiveram dedos das mãos prensados entre o cabo do carrinho de transporte de concreto e os marcos de portas. Considerando a ação de empurrar o carrinho que culminou com o impacto contra a porta, a aplicação do algoritmo seguiu a sequência 1-2-3-4-5-10, caracterizando um deslize. Vale salientar que na pergunta 3 foi avaliado somente se foi seguido o procedimento correto de empurrar o carrinho, não sendo avaliada a dimensão do procedimento associada ao uso de luvas.

- Recomendação 2: em caso de dúvidas na resposta a alguma questão, uma boa prática é testar as diferentes alternativas, verificando se o resultado final será ou não o mesmo. Como exemplo, pode ser citado o caso em que, durante o corte de uma barra de aço na serra policorte, uma faísca proveniente do disco de corte atingiu o olho do operador, que usava óculos de segurança com proteções laterais. Tanto na hipótese de considerar que o procedimento era incorreto, pois os óculos não eram do modelo adequado (sequência 1-2-10), quanto na hipótese de considerar que os óculos eram adequados, mas talvez estivessem danificados (sequência 1-2-3-410), as conclusões são de que não houve erro do trabalhador;

- Recomendação 3: com base na recomendação 1, percebe-se que é possível, mesmo sem a aplicação do algoritmo, concluir que não houve nenhum erro dos trabalhadores envolvidos. Tais casos incluem as situações em que não houve nenhuma ação ou decisão dos trabalhadores que sirvam de referência para a aplicação do algoritmo. Por exemplo, pode 
ser citado o acidente em que o escoramento de uma vala de fundação não suportou os esforços e houve soterramento parcial de um trabalhador. Nesse caso, embora a aplicação do algoritmo fosse dispensável, ainda assim ele foi utilizado (sequência 1-2-3-410) com a finalidade de validá-lo em tais cenários;

- Recomendação 4: a aplicação do algoritmo deve ser realizada em equipe e contar com a participação de membros experientes no domínio em questão. De fato, dois dos três autores desse estudo são engenheiros civis, sendo que um deles também é engenheiro da empresa investigada, o que facilitou a compreensão dos eventos, suas causas e ações corretivas. No estudo de Costella e Saurin (2005), houve colaboração passiva dos técnicos de segurança da empresa, que se limitaram a fornecer informações, mas não aplicaram diretamente o algoritmo. Já no estudo de Bassols, Ballardin e Guimarães (2007), os pesquisadores não tiveram a oportunidade de discutir o uso da ferramenta com representantes da empresa.

\subsection{Modificações no algoritmo e recomendações para interpretação das perguntas}

Neste item, são apresentadas sete modificações ou recomendações para interpretação das perguntas do algoritmo, visando principalmente sua adaptação ao contexto dos canteiros de obras:

- Modificação ou recomendação 1: a interpretação da pergunta 2 ("o procedimento e/ou treinamento era adequado e aplicável?”) pode ser difícil quando não há procedimentos documentados que especifiquem os passos e regras aplicáveis à tarefa, como era o caso na construtora investigada. Nesse caso, propõe-se que o procedimento adotado como referência deve ser: aquele descrito em normas, como, por exemplo, a NR-18 ou normas da ABNT; ou aquele tacitamente aceito como correto por trabalhadores e gerentes.

Se ficar evidente, a partir de entrevistas, que não existe um consenso acerca de qual é o procedimento tacitamente aceito como correto, a resposta à pergunta 2 deve ser negativa. Essa situação pode ser ilustrada por um acidente durante a desmontagem da torre do elevador de carga. Nesse evento, um trabalhador que estava na parte interna do edifício recebendo os elementos da torre (cada um com dimensões de $1 \mathrm{~m} \times 2 \mathrm{~m}$ ) fraturou um dedo ao prensar a mão entre a peça recebida e a estrutura da torre. A investigação teve a sequência 1-2-10 no algoritmo, para todos os membros da equipe, deixando claro que o procedimento era inadequado. De fato, não havia consenso acerca de quantas pessoas deveriam retirar as peças, acerca da necessidade ou não do uso de luvas nessa tarefa, nem acerca de quais deveriam ser as competências dos funcionários envolvidos. Apesar do risco de queda de altura intrínseco a essa tarefa, é provável que a falta de consenso decorra de que ela normalmente é executada apenas uma vez durante a execução de uma obra.

- Modificação ou recomendação 2: uma vez que a proposta anterior seja levada em conta, torna-se desnecessário fazer menção à palavra treinamento nas perguntas 2 , 3 e 6 . Caso a palavra procedimento incorpore aqueles que são tácitos, isso implica que ela também engloba as situações em que o operador conhece os procedimentos apenas por meio de treinamentos, sejam eles formais ou informais a partir do aprendizado com colegas mais experientes;

- Modificação ou recomendação 3: a pergunta 1 ("o trabalhador conhecia os procedimentos e/ ou foi treinado para essa tarefa?") foi de difícil interpretação quando não havia procedimentos documentados e quando o termo procedimento foi interpretado segundo a proposta (a) anteriormente apresentada. Deste modo, propõe-se que a pergunta 1 seja substituída pela seguinte questão: era uma tarefa rotineira e/ou habitual para o trabalhador? Como exemplo do uso dessa pergunta, pode ser citado um acidente no qual um trabalhador, sem óculos de proteção, sofreu respingos de concreto no olho durante uma concretagem. Embora ele não conhecesse o procedimento ideal para essa situação (usar óculos), nem tivesse recebido treinamento formal para sua realização, a atividade era rotineira. Assim, nesse caso a resposta à pergunta 1 foi positiva.

Vale salientar que na versão do algoritmo apresentada na Figura 1, o investigador poderia ser induzido a atribuir uma resposta negativa para a pergunta 1, o que implicaria no pressuposto da existência de um desvio de função (deliberado ou não), o que não corresponde ao contexto do exemplo citado.

- Modificação ou recomendação 4: propõe-se que na pergunta 6 ("se o procedimento e/ou treinamento tivesse sido seguido, o incidente ocorreria?") seja acrescentada a expressão "com a mesma severidade". A necessidade dessa mudança é ilustrada pela análise da decisão de não usar luvas nos já comentados acidentes em que os trabalhadores tiveram os dedos prensados contra o marco de uma porta ao empurrarem um carrinho de mão. Caso o algoritmo fosse usado na sua forma original, essa decisão seria analisada de acordo com a sequência 1-2-3-6-10 (não houve erro do trabalhador). Contudo, apesar de não evitar a ocorrência do acidente, as luvas provavelmente minimizariam suas consequências, o que é justificativa suficiente para seu uso. Deste modo, segundo essa proposta, a análise da decisão de não usar luvas leva o algoritmo à sequência 1-2-36-7-8-10 (violação), opção que foi considerada na 
tabulação dos resultados. Esses acidentes também indicaram, como oportunidade de melhoria, que o projeto dos carrinhos deveria ser reavaliado, de modo a facilitar sua passagem pelas portas.

- Modificação ou recomendação 5: a pergunta 3 (“o procedimento e/ou treinamento foi seguido?") deve ser respondida sob a perspectiva de todos os envolvidos na equipe que executou a tarefa, ao invés de apenas sob a perspectiva do trabalhador para o qual o algoritmo está sendo aplicado. lsso significa que, caso qualquer membro da equipe não tenha seguido o procedimento, a resposta à pergunta 3 deve ser negativa. Dois acidentes similares ilustram a necessidade dessa recomendação, envolvendo eventos em que trabalhadores tiveram os pés perfurados por pregos que estavam em pedaços de madeira espalhados pelo piso. Adotando a recomendação proposta, a sequência de aplicação do algoritmo é 1-2-3-6-7-10 (não houve erro do trabalhador), considerando que outros membros da equipe não seguiram o procedimento de retirar os pregos das madeiras e armazená-las em pilhas, de forma organizada;

- Modificação ou recomendação 6: o estudo de caso indicou que a pergunta 7 ("outro trabalhador se comportaria do mesmo modo em uma mesma situação?”) continua subjetiva mesmo quando é possível comparar o desempenho de um trabalhador com seus colegas de equipe. De fato, quando há uma equipe envolvida, a subjetividade ainda persiste na medida em que deveria ser comparado o desempenho de diferentes equipes.

Deste modo, propõe-se que, em caso de dúvidas, seja usada uma pergunta de apoio como subsídio para responder à pergunta 7 (sugere-se que essa pergunta não seja incluída na representação gráfica do algoritmo): os recursos para aplicação do procedimento estavam disponíveis, não havendo dependência de outros? Tal pergunta visa explicitar um dos principais motivos que podem levar ao descumprimento de um aparente bom procedimento, qual seja a falta dos recursos (por exemplo, recursos materiais ou humanos) necessários para sua aplicação. Caso a resposta seja positiva (os recursos estavam disponíveis) isso significa que provavelmente outros trabalhadores não agiriam da mesma forma. Caso a resposta seja negativa, isso indica que provavelmente outros trabalhadores agiriam da mesma forma, caracterizando então a ausência de erro.

São citados quatro exemplos que justificam a contribuição da pergunta de apoio, sendo que os dois primeiros resultaram em violações e os dois últimos na ausência de erro. 0 primeiro exemplo diz respeito a um acidente durante o transporte de barras de aço por três trabalhadores. Ao chegarem ao local de descarga, o feixe de barras se abriu e um dos trabalhadores teve a mão prensada entre os ferros. Contudo, esse trabalhador era o único dos três que não utilizava luvas de raspa, as quais, segundo a investigação, estavam disponíveis. Deste modo, considerando a decisão de não usar luvas, a aplicação do algoritmo para o trabalhador lesionado teve a sequência 1-2-3-6-7-8-10 (violação).

Já o segundo exemplo, diferentemente do anterior, ilustra uma situação em que todos os membros da equipe agiram da mesma forma. Nesse caso, três trabalhadores preparavam uma betoneira para um curto deslocamento manual, sem terem acionado uma alavanca de segurança que manteria fixo, sobre a betoneira, o seu carregador. Contudo, um dos membros da equipe cruzou em frente à betoneira (a regra tácita seria sempre cruzar atrás da betoneira, visto que o carregador só poderia cair para a frente) no mesmo momento em que o carregador caiu, atingindo-o nas costas. Nesse caso, os recursos para executar a ação correta estavam disponiveis (a alavanca estava em boas condições e era acessível) e a aplicação da regra era imediata, dependendo somente da ação dos trabalhadores. Na aplicação do algoritmo, a decisão de não fixar a alavanca de segurança foi contabilizada como três violações, uma para cada membro da equipe.

Entretanto, outros acidentes revelaram situações em que os recursos não estavam disponíveis e o procedimento não era de fácil aplicação. Em um destes casos, o trabalhador usou uma escada de mão como apoio para pregar a fôrma de uma viga e, provavelmente em função de um desequilíbrio, bateu o martelo contra um dedo, fraturando-o. Em outro caso, para descer de um andaime suspenso, um trabalhador pulou de uma altura de 1,50 m para chegar ao chão, perdeu o equilíbrio e quebrou um braço. Em ambos os acidentes, o algoritmo indicou a sequência 1-2-3-6-7-10 (não houve erro). De fato, os procedimentos estabelecidos na NR-18 e as boas práticas no setor recomendam o uso de um andaime como acesso às vigas e o uso de uma escada para descer dos andaimes. Contudo, tais recursos (andaime e escada) não foram disponibilizados, fazendo com que as escolhas dos trabalhadores fossem necessárias e encaradas como normais.

- Modificação ou recomendação 7: a versão original da pergunta 8 (“o erro foi intencional?”) foi substituída pela seguinte sentença: a ação e/ou decisão foi intencional? 0 objetivo dessa mudança é explicitar o conceito de erro apresentado no item 2 deste artigo.

Considerando todas as propostas apresentadas, pode-se chegar a uma nova versão do algoritmo adequada ao contexto de canteiros de obra (Figura 2). 


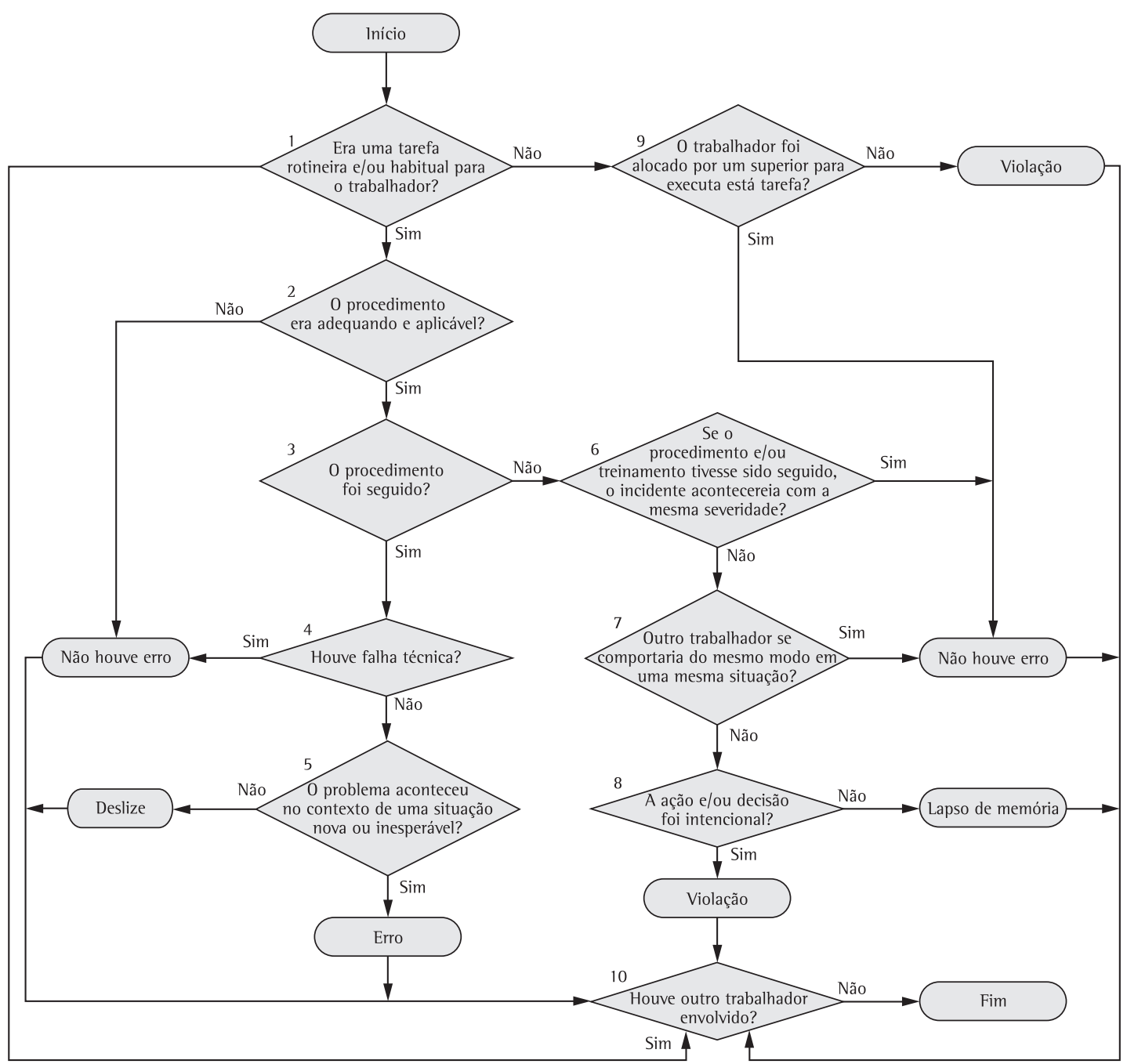

Figura 2. Nova versão do algoritmo, adaptada ao contexto de canteiros de obras.

\subsection{Tipos de erros nos acidentes investigados}

Os 19 acidentes investigados possibilitaram a aplicação do algoritmo 34 vezes, sendo que 22 destas aplicações se referiram aos pontos de vista dos trabalhadores lesionados e 12 se referiram aos pontos de vista dos colegas de equipe. Tanto sob a perspectiva dos lesionados, quanto sob a perspectiva dos seus colegas, o número de aplicações do algoritmo foi superior ao número de trabalhadores envolvidos. Por exemplo, enquanto houve 19 trabalhadores lesionados, o algoritmo foi aplicado 22 vezes para eles, visto que em alguns eventos houve mais de uma ação ou decisão que serviu de referência para a aplicação. A Tabela 1 sumariza os tipos de erros para todos os trabalhadores, apenas para os lesionados e apenas para os colegas de equipe.
Com base na Tabela 1, pode-se perceber que, seja qual for a perspectiva, a categoria não houve erro do trabalhador foi preponderante. Tais resultados são consistentes com um estudo realizado por Suraji, Duff e Peckitt (2001), que analisou as causas de 500 acidentes em canteiros de obras no Reino Unido. Nesse estudo, os autores concluíram que em 70,1\% dos eventos não houve qualquer erro dos trabalhadores envolvidos nos acidentes. Também houve consistência com um estudo realizado por Saurin et al. (2005), os quais investigaram a frequência com que erros dos trabalhadores contribuíram em falhas de planejamento e controle da SST em cinco canteiros de obras. Nesse estudo, a conclusão foi de que, considerando a média dos cinco canteiros, não houve qualquer erro dos trabalhadores em 72,8\% dos eventos. Os estudos de Suraji, Duff e Peckitt (2001) e Saurin et al. (2005) utilizaram classificações de tipos de erros diferentes 
Tabela 1. Tipos de erros nos acidentes investigados em canteiros de obras.

\begin{tabular}{cccc} 
& $\begin{array}{c}\text { Aplicações para todos os } \\
\text { trabalhadores }(\mathrm{n}=34)\end{array}$ & $\begin{array}{c}\text { Aplicações para os trabalhadores } \\
\text { lesionados }(\mathrm{n}=22)\end{array}$ & $\begin{array}{c}\text { Aplicações para os colegas de } \\
\text { equipe }(\mathrm{n}=12)\end{array}$ \\
\hline Não houve erro & $24(70,5 \%)$ & $15(68,2 \%)$ & $9(75,0 \%)$ \\
Violações & $8(23,5 \%)$ & $5(22,7 \%)$ & $3(25,0 \%)$ \\
Deslizes & $2(5,9 \%)$ & $2(9,1 \%)$ & $0(0,0 \%)$ \\
\hline
\end{tabular}

Tabela 2. Sequências na aplicação do algoritmo.

\begin{tabular}{cr}
\hline Sequência & Frequência \\
\hline $1-2-3-6-7-10$ (não houve erro) & $14(41,2 \%)$ \\
$1-2-3-6-7-8-10$ (violação) & $8(23,5 \%)$ \\
$1-2-3-4-10$ (não houve erro) & $6(17,6 \%)$ \\
$1-2-10$ (não houve erro) & $4(11,8 \%)$ \\
$1-2-3-4-5-10$ (deslize) & $2(5,9 \%)$ \\
\hline
\end{tabular}

da usada neste estudo, inviabilizando comparações para cada tipo de erro.

A Tabela 2 apresenta a frequência com que cada sequência do algoritmo foi utilizada, o que ajuda a esclarecer as diferentes naturezas das situações em que não houve erro do trabalhador. A alta frequência da sequência 1-2-3-6-7-10 significa, em geral, que 0 descumprimento de boas regras era a prática comum e aceita como normal por trabalhadores e gerentes, bem como que os trabalhadores tiveram um papel passivo na sequência de eventos.

Em particular, os colegas de equipe desempenharam papel reativo e passivo na grande maioria dos eventos. Apesar de eles terem cometido apenas 3 violações, também não contribuíram para alertar os colegas acerca dos perigos. Tais dados podem indicar que as equipes carecem de habilidades de percepção de riscos, comunicação e coordenação, que normalmente não são enfatizadas nos treinamentos de operários da construção civil.

Também é importante observar que duas categorias de erros não estiveram associadas a nenhuma aplicação do algoritmo. Em relação à ausência de erros no nível do conhecimento, isso é compatível com a natureza das tarefas executadas nos canteiros da empresa investigada, as quais são relativamente repetitivas e previsíveis. De outro lado, tais tipos de tarefas são suscetíveis a lapsos de memória, especialmente em ambientes dinâmicos como os canteiros de obras, nos quais tendem a haver diversas interrupções nas atividades rotineiras que dão origem a lapsos. A ausência de lapsos pode significar tanto que suas consequências não têm sido suficientemente fortes para contribuir em acidentes, quanto que tais erros são difíceis de serem identificados por geralmente implicarem na omissão de alguma atividade, o que, por sua vez, torna o erro mais difícil de ser observado.
Considerando os resultados das Tabelas 1 e 2 conjuntamente, no contexto da construtora investigada, há evidências de que o maior potencial para avanços em SST está na melhoria das práticas de gestão, de modo que as dificuldades intrínsecas ao setor (por exemplo, alta rotatividade da mão de obra e seu baixo nível de educação formal) não parecem ser os principais fatores limitantes. Em particular, nas obras investigadas os fatores causais estiveram fortemente associados a problemas gerenciais, tais como:

- À inexistência de procedimentos formais, havendo confiança excessiva, tanto de gerentes quanto de operários, no conhecimento tácito desses últimos. Alguns procedimentos tácitos não eram consensuais ou, quando havia consenso, eles eram notadamente equivocados e em conflito com a legislação e as boas práticas do setor (por exemplo, o não uso de óculos de proteção em atividades de concretagem era aceito como normal);

- À precária cultura de segurança, refletida na desinformação dos trabalhadores acerca da necessidade de uso dos EPI e na falta de fiscalização por parte dos gerentes. A cultura de segurança é uma dimensão da cultura organizacional, influenciando as atitudes e comportamentos dos membros da empresa em relação à SST. Quando a SST é um forte valor organizacional, as violações desnecessárias de bons procedimentos são menos frequentes (COOPER, 2000);

- A falhas técnicas em barreiras físicas (por exemplo, o colapso do escoramento de um talude) ou simplesmente a ausência de barreiras físicas exigidas pelas normas (por exemplo, o colapso de outro talude, que não possuía qualquer escoramento).

A Tabela 3 apresenta uma comparação dos resultados dessa pesquisa com os dois estudos anteriores que originaram a ferramenta. Pode-se perceber uma maior incidência de violações nos acidentes da construção civil, o que é coerente com a notoriamente mais fraca cultura de segurança na construtora investigada, em comparação com as empresas dos outros estudos de caso. Entretanto, assim como nos demais estudos, a investigação nos canteiros de obras também reforçou a grande participação da categoria não houve erro do trabalhador, apontando que, independentemente da cultura de segurança mais ou menos forte, as falhas organizacionais, ao invés de fatores individuais, desempenharam papel decisivo dentre os fatores causais. 
Tabela 3. Comparação dos resultados desse estudo com os dois anteriores que originaram o algoritmo.

\begin{tabular}{cccc}
\hline & $\begin{array}{c}\text { Construção civil } \\
(\%)\end{array}$ & $\begin{array}{c}\text { Fábrica de máquinas agricolas } \\
\text { (COSTELLA; SAURIN, 2005) } \\
(\%)\end{array}$ & $\begin{array}{c}\text { Distribuidora de combustíveis } \\
\text { (BASSOLS; BALLARDIN; GUIMARÃES, 2007) } \\
(\%)\end{array}$ \\
\hline Não houve erro & 70,5 & 30,6 & 73,8 \\
Violações & 23,5 & 16,7 & 12,2 \\
Deslizes & 5,9 & 41,7 & 12,2 \\
Erros no nível do conhecimento & 0,0 & 11,1 & 0,0 \\
Lapsos & 0,0 & 0,0 & 2,4 \\
\hline
\end{tabular}

\section{Conclusões}

Este trabalho teve como principal objetivo identificar oportunidades de aperfeiçoamentos em um método de classificação de tipos de erros humanos, com base na sua aplicação para a investigação de acidentes de trabalho em canteiros de obras. Diferentemente das aplicações anteriores do método, neste estudo a investigação dos acidentes não foi baseada em relatórios de investigação preparados pela empresa, cabendo aos pesquisadores a reconstituição dos fatos. Entretanto, isso não foi necessariamente uma desvantagem em relação aos estudos anteriores, visto que, ao contrário daqueles, desta vez os pesquisadores tiveram amplo acesso para entrevistar os envolvidos nos acidentes e visitar os cenários em que ocorreram.

Com base no estudo de caso, foram estabelecidas quatro recomendações para aplicação do método: a) identificar episódios que sirvam de referência para a análise, tais como ações ou decisões dos trabalhadores; b) testar diferentes alternativas em caso de dúvidas, visto que frequentemente o resultado final será o mesmo; c) reconhecer que a aplicação pode ser desnecessária, ou ser feita apenas com a finalidade de testar a ferramenta, nas situações em que não há ações ou decisões dos trabalhadores que sirvam de referência; d) aplicar o algoritmo em equipe e com a participação de especialistas no domínio em questão. Além disso, é fundamental enfatizar que o algoritmo não deve ser utilizado como uma ferramenta para identificar o grau de culpabilidade dos envolvidos nos acidentes. A classificação dos tipos de erros é apenas o ponto de partida para uma investigação mais aprofundada que deve buscar causas raízes da falta de segurança. Os resultados também contribuem para a formação de bancos de dados e identificação de tendências de longo prazo, com o consequente direcionamento das ações preventivas conforme os tipos de erros mais frequentes.

Esse estudo também resultou em uma nova versão do algoritmo, adaptada ao contexto dos canteiros de obras. A necessidade dessa nova versão decorreu das dificuldades de interpretação das perguntas em um ambiente que não possuía procedimentos formais e no qual o descumprimento de boas práticas de
SST pareceu ser a regra. Vale salientar que o fato de 70,5\% das aplicações ter indicado a ausência de erro, é forte o indício de que as ações de SST devem ser prioritariamente dirigidas à gestão dos empreendimentos, ao invés de serem focadas nos comportamentos dos trabalhadores.

Em decorrência do que foi realizado nesta pesquisa, também podem ser identificadas oportunidades para estudos futuros, tais como: a) desenvolvimento de recomendações mais detalhadas para apoiar a identificação de respostas para cada pergunta do algoritmo, o que pode incluir um roteiro de perguntas de apoio; b) aplicação do método conjuntamente com outras ferramentas de investigação de acidentes, identificando as complementaridades entre elas; c) aplicação do método em outros setores e em outras empresas de construção civil, cujas características de processos construtivos e sistemas gerenciais sejam diferentes da empresa investigada. Nesse sentido, deve ser esperada a necessidade de realizar novas adaptações no método na medida em que ele seja aplicado em novos contextos, como ocorreu nos estudos realizados até o momento.

\section{Referências}

BAKER, D.; KROKOS, K. Development and validation of aviation causal contributors for error reporting systems (ACCERS). Human Factors, v. 43, n. 2, p. 185-199, 2007. http://dx.doi.org/10.1518/001872007X312432

BASSOLS, F. F.; BALLARDIN, L.; GUIMARÃES, L. B. M. Análise dos tipos de erros em uma distribuidora de produtos derivados de petróleo. In: ENCONTRO NACIONAL DE ENGENHARIA DE PRODUÇÃO - ENEGEP, 27, 2007. Anais... ABEPRO, 2007.

COOPER, M. D. Towards a model of safety culture. Safety Science, v. 36, p. 111-136, 2000. http://dx.doi. org/10.1016/S0925-7535(00)00035-7

COSTEllA, M.; SAURIN, T. A. Proposta de método para identificação de tipos de erros humanos. In: ENCONTRO NACIONAL DE ENGENHARIA DE PRODUÇÃO - ENEGEP, 25., 2005. Anais... ABEPRO, 2005.

DEKKER, S. Just Culture: balancing safety and accountability. London: Ashgate, 2007.

DEKKER, S. The Field Guide to Human Error Investigations. London: Ashgate, 2002. 
GRABOWSKl, M. et al. Human and organizational error data challenges in complex, large scale systems. Safety Science, v. 47, n. 8, p. 1185-1194, 2009. http://dx.doi. org/10.1016/j.ssci.2009.01.008

HINZE, J. Making zero injuries a reality. Gainesville: Construction Industry Institute, 2002. 110 p. Report 160.

RASMUSSEN, J.; PETERSEN, A.; GOODSTEIN, L. Cognitive Systems Engineering. New York: John Wiley \& Sons, 1994.

REASON, J. Human Error. Cambridge: Cambridge University Press, 1990.

REASON, J. Managing the Risks of Organizational Accidents. Burlington: Ashgate, 1997. $252 \mathrm{p}$.

REASON, J. The Human Contribution: unsafe acts, accidents and heroic recoveries. Ashgate, 2008.
SANDERS, M.; McCORMICK, E. Human Factors in Engineering and Design. 7. ed. New York: McGraw-Hill, 1993.

SAURIN, T. A. et al. An algorithm for classifying error types of front-line workers based on the SRK framework. International Journal of Industrial Ergonomics, v. 38, p. 1067-1077, 2008. http://dx.doi.org/10.1016/j. ergon.2008.02.017

SAURIN, T. A.; FORMOSO, C. T.; CAMBRAIA, F. B. Analysis of a safety planning and control model from the human error perspective. Engineering, Construction and Architectural Management, v. 12, n. 3, p. 283-298, 2005. http:// dx.doi.org/10.1108/09699980510600134

SURAJI, A.; DUFF, R.; PECKITT, S. Development of causal model of construction accident causation. Journal of Construction Engineering and Management, v. 127, n. 4, p. 337-344, 2001. http://dx.doi.org/10.1061/ (ASCE)0733-9364(2001)127:4(337)

\title{
An algorithm for classifying error types of front-line workers: a case study in accidents in construction sites
}

\begin{abstract}
The objective of this study is to propose improvements in the algorithm for classifying error types of front-line workers. The improvements have been identified on the basis of testing the algorithm in construction sites, an environment where it had not been implemented it. To this end, 19 occupational accidents which occurred in a small construction company were investigated, and the error types of both injured workers and team members were classified. The results indicated that there was no error in 70.5\% of the 34 times the algorithm was applied, providing evidence that the causes were strongly linked to organizational factors. Moreover, the study presents not only recommendations to facilitate the interpretation of the questions that constitute the algorithm, but also changes in some questions in comparison to the previous versions of the tool.
\end{abstract}

\section{Keywords}

Accident investigation. Human error. Safety. Construction. 